Abdulhameed N. Aldabagh BDS, MSc. PhD. (Lec.)

\section{Heat Generation by Diode Laser (1064-nm) on Dental Implants. (An in vitro study)}

\author{
Department of Oral and Maxillofacial Surgery \\ College of Dentistry, University of Mosul
}

\begin{abstract}
الخلاصة

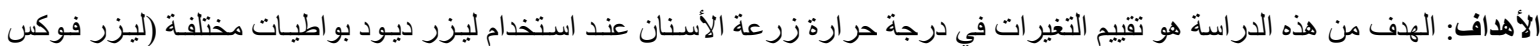

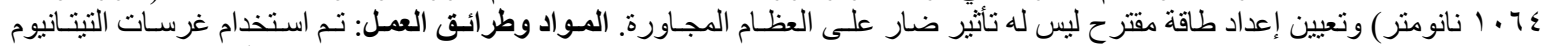

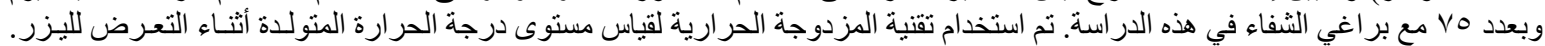

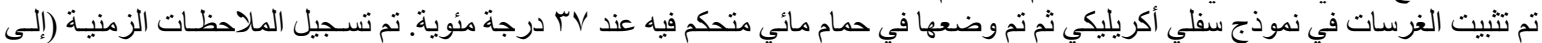

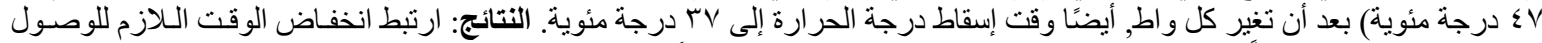

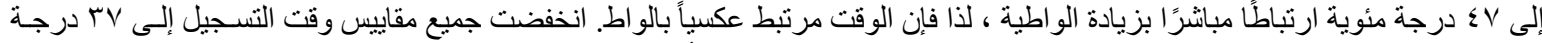

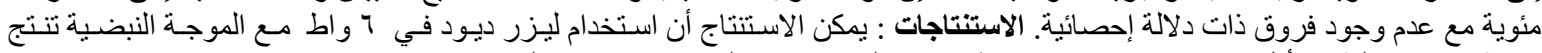

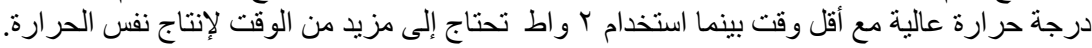

\begin{abstract}
Aims: The aim of this study was to assess temperature changes of dental implant body when using different wattage of diode laser (Fox laser 1064-nm) and set a proposed power setting that has no detrimental effect on adjacent bone. Materials and Methods: Seventy-five Titanium implants with healing screws were used in this study. Thermocouple technology was used to measure the temperature level generated in the dental implant body when being exposed to laser. The implants were fixed in an acrylic mandible model and then placed in a controlled water bath at $37{ }^{\circ} \mathrm{C}$. Time to reach a temperature degree of $47{ }^{\circ} \mathrm{C}$ were recorded after each wattage as well as the dropping time of temperature to reach a degree of $37^{\circ} \mathrm{C}$ was recorded. Results: The decrease in time needed to reach $47^{\circ} \mathrm{C}$ was directly related to an increase in wattage and as such the time is inversely related to wattage. All the recording time measures dropped to $37{ }^{\circ} \mathrm{C}$ with no significant differences. Conclusion: It can be concluded that using diode laser in at 6 wattages with pulsed wave settings produced high temperature with minimum time compared when using 2 wattage settings which needed more time to produce the same heat
\end{abstract}

Keywords: Dental implant, laser, Heat generation.

Aldabagh AN. Heat Generation by Diode Laser (1064-nm) on Dental Implants. (An in vitro study). $A l-$ Rafidain Dent J. 2021; 21(2):240-250.

DOI: 10.33899/rdenj.2021.129869.1099＜noBreak>（C2021, College of Dentistry, University of Mosul.

Received: 6/4/2021 Sent to Referees: 10/4/2021_ Accepted for Publication: 26/9/2021

This is an open access article under the CC BY 4.0 license (http://creativecommons.org/licenses/by/4.0/).

\section{INTRODUCTION}

The use of endosseous implants in dentistry

has increased dramatically over the last 20 years ${ }^{(1,2)}$. With dental implant therapy complications may occur which could either be prosthetic or biological complications or both. Suc- 
cess has been demarcated recently ${ }^{(3-5)}$. Periimplantitis is the most common biological complication around dental implants. A current consensus report concluded that peri-implantitis is a bacterially induced inflammation of the supporting peri-implant tissues leading to nonreversible bone destruction ${ }^{(6-8)}$. The incidence of peri-implantitis fluctuates from 11.3 to $47.1 \%$ after 8 years. ${ }^{(9)}$ Numerous treatments have been recommended for peri-implantitis in the literature such as physical method plastic curettes, scaling, ultrasound. ${ }^{(10)}$, local chemical antibiotics, antiseptic solutions. (11) systemic methods, ${ }^{(12)}$ or a combination of these. ${ }^{(13,14)}$ The use of laser in the dental field has encouraged research for determining its effectiveness in the treatment of peri-implantitis. ${ }^{(15,16)}$ The revolution for dental laser came in the middle of the 1990s. Many laser types with corresponding wavelengths, diode laser rapidly began establishing itself as a compact, competitively priced, and versatile accompaniment to the dentist's collection mostly used on soft tissue applications ${ }^{(17)}$ Diode lasers can be used for numerous dental events which are frequently soft tissue procedures. ${ }^{(18,19)}$ Diode lasers have been suggested for uncovering submerged implants. ${ }^{(20,21)}$ decontaminating implant surfaces when treating peri-implantitis ${ }^{(22)}$ and, periodontal pocket therapy (23). The thermal effect of laser beams on implant surfaces is widely studied. These studies have revealed that thermal injury at the bone-implant site impedes the regenerative reaction of bone healing, hence reducing osseointegration leading to subsequent implant mobility. ${ }^{(24-26)}$ It has been established that if bone is warmed up to a temperature of $47^{\circ} \mathrm{C}$ for one minute, bone necrosis, which obstructs the osseointegration of an implant, can occur. However, heating to temperatures lower than $47^{\circ} \mathrm{C}$ did not seem to affect the bone tissue at the microscopic level, but vascular injury, as evidenced by increased capillary leakage, could not be excluded at even lower temperatures. ${ }^{(27)}$ The aim of the current invitro study was to assess temperature changes of dental implant body when using different wattage settings of diode laser (Fox laser 1064-nm) and set a proposed power setting that has no detrimental effect on adjacent bone.

\section{MATERIALS AND METHODS}

This study was conducted at the department of Oral and Maxillofacial Surgery / College of Dentistry / University of Mosul. Dental implants with SLA surfaces were used in this study $(3.3 * 10 \mathrm{~mm})$ (Leader, made in Italy). A motor system (NSK, made in Japan) was used for insertion of the dental implant (Figure 1). 
Diode laser (FOX Laser, ARC Laser $\mathrm{GmbH}$, Germany) was used in pulse mode with a spot size of $600 \mu$ (puls on $50 \mathrm{~ms}$ and puls off $100 \mathrm{~ms}$ (Figure 2). A Synthetic mandible model (Sawbones, Swedish-made) produced from solid foam was used as a model for implant insertion (Figure 3). A water bath with a thermostat-

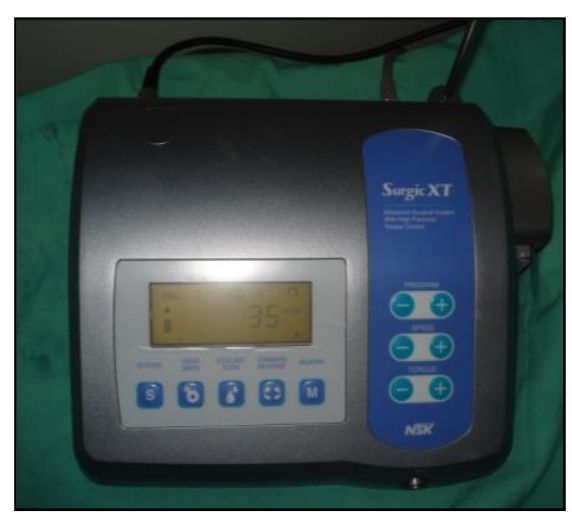

Figure (1): NSK motor system ic temperature-control device maintaining the water temperature at $37^{\circ} \mathrm{C}$ (C.K type KI\&BNT made in china) was used (Figure 3). Thermocouple electrodes (K-type made in china) were used to measure the temperature (Figure 3). An electronic timer was used to record reading in seconds ${ }^{(28) .}$

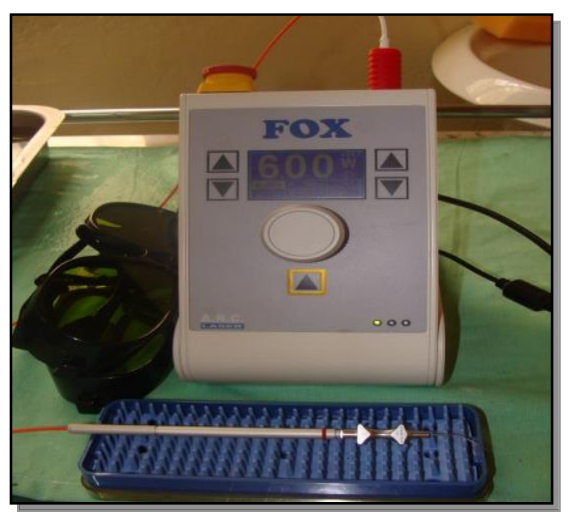

Figure (2): Diode laser

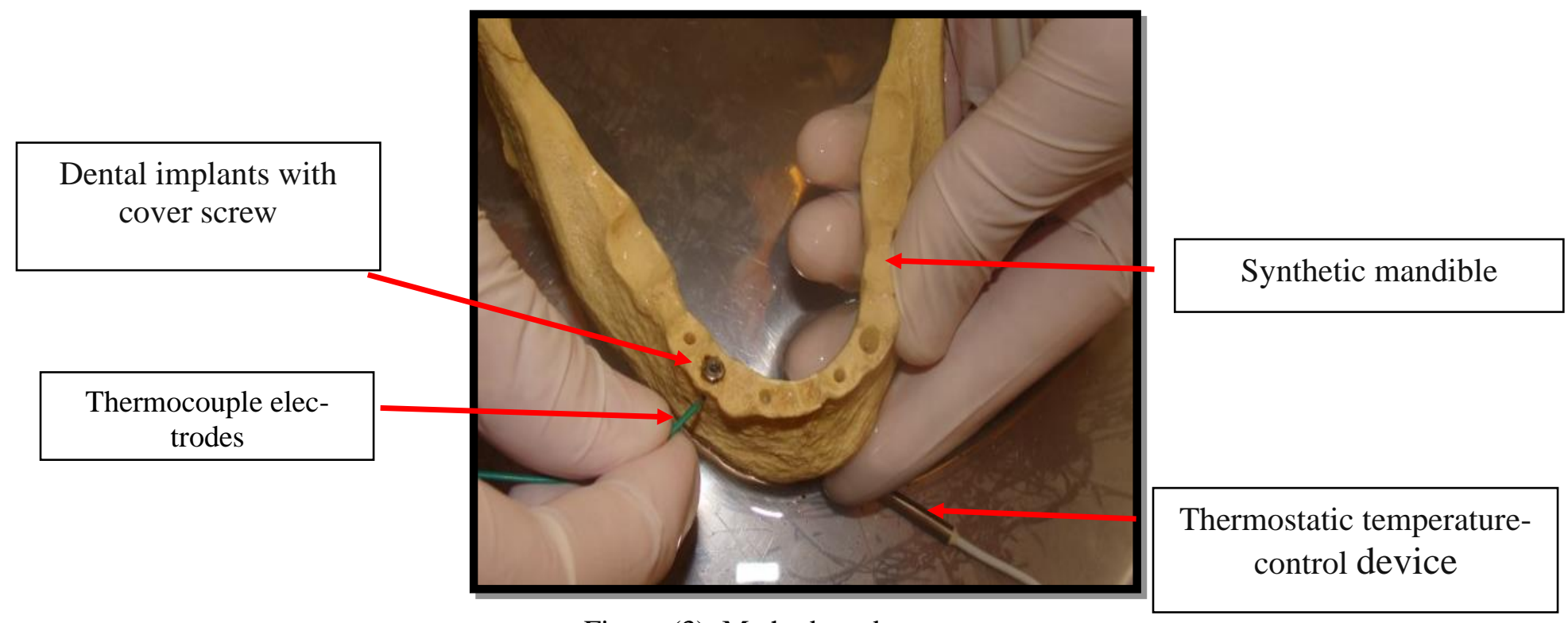

Figure (3): Method used.

Dental implants with an SLA surface with $3.3 \mathrm{~mm}$ in diameter and $10 \mathrm{~mm}$ in length were inserted in the mandible model by using a mo- tor system of dental implant preparation which began with an initial Linderman drill $(2.2 \mathrm{~mm})$ then a first drill $(2.6 \mathrm{~mm})$ followed by final 
drill and finally by countersink. The drill speed was set up to 1062 RPM and torque kept at 50 $\mathrm{n} \backslash \mathrm{cm}$ and gear ratio stabilized at 1:32. After completion of implant insertion, the cover screw was placed in its position. The mandible model was immersed in the water bath with a thermostatic control mechanism keeping the water temperature at $37^{\circ} \mathrm{C}$. Thermocouple electrode heads were attached to the exterior surface of the fixed implant at its cervical facets and the head of the thermocouple wires were insulated from water. The tip of the laser was positioned in non-contact mode two millimeters away from the center of the cover screw perpendicular to the implant long axis and then laser exposure was initiated following the protocol of safety. The dental implants were separated into five groups according to laser watt used $(2,3,4,5,6$ watts respectively) with each group of 15 dental implants making a total of 75 implants and 20 temperature readings in each group. An electronic timer was used to measure the time needed to reach $47^{\circ} \mathrm{C}$ and the time needed to drop to $37^{\circ} \mathrm{C}$ after laser application.

\section{Statistical analysis}

Data were processed using the statistical analysis program (SPSS version 21 for Windows 10 Pro), Lenovo laptop, think pad L460. MannWhitney test was used for comparing between different powers and time during temperature rises to $47^{\circ} \mathrm{C}$. The relation between the time and the powers used was assessed using Kruskal -Wallis for dropping of temperature to $37^{\circ} \mathrm{C}$. The level of significance considered was set at $\mathrm{p}<0.05$.

\section{RESULTS}

The mean time required to raise the temperature to $47^{\circ} \mathrm{C}$ at 2 watts was (126) seconds, at 3 watts (93.2) seconds, at 4 watts (73.7) seconds, at 5 watts (68.4) seconds and at 6 watts was (61.6) seconds. The mean ranks and significance as calculated by the KruskalWallis test for time in seconds needed to rise to $47^{\circ} \mathrm{C}$ disclosed a significant difference between groups. The results revealed in the MannWhitney test (Table2) showed a significant difference in time (seconds) to rise to $47^{\circ} \mathrm{C}$ between each reading.

Table (1): Mean ranks and p-value of Kruskal -Wallis test for temperature $47^{\circ} \mathrm{C}$ rise at different powers with mean time in second to reach $47 \mathrm{c}$.

\begin{tabular}{cccc}
\hline Power in Watt & Meantime in second to reach $47^{\circ} \mathrm{C}$ c & Std. Deviation & Mean rank \\
\hline 2 & 126 & 2.4 & 1350 \\
3 & 93.2 & 1.5 & 1050 \\
4 & 73.7 & 0.77 & 750 \\
5 & 68.4 & 1.4 & 450 \\
6 & 61.6 & 0.85 & 150 \\
p-value & & & 0.00 \\
\hline
\end{tabular}


Table (2): Mann-Whitney test for temperature $47^{\circ} \mathrm{C}$ at different powers

\begin{tabular}{cc}
\hline Relation between Different power in watts & p-value \\
\hline $2-3$ & 0.00 \\
$2-4$ & 0.00 \\
$2-5$ & 0.00 \\
$2-6$ & 0.00 \\
$3-4$ & 0.00 \\
$3-5$ & 0.00 \\
$3-6$ & 0.00 \\
$4-5$ & 0.00 \\
$4-6$ & 0.00 \\
$5-6$ & 0.00 \\
\hline
\end{tabular}

Statically significant at $\mathrm{p} \leq 0.05$

Concerning the time that was needed to drop temperatures to $37^{\circ} \mathrm{C}$ at different powers, Kruskal -Wallis test results showed no significant difference between groups and as shown in (Table 3). The mean time needed for dropping of temperature to $37{ }^{\circ} \mathrm{C}$ at 2 watts was (59) seconds, at 3 watts (59.1) seconds, at 4 watts was (59.1)) seconds, at 5 watts (59.1)) seconds and at 6 watts was (58.9) seconds. Mann-
Whitney test results showed no significant differences regarding drop of temperature to $37^{\circ} \mathrm{C}$ when comparing between each reading with another and shown in (Table 4). As an overall observation, temperatures in the implant body increased as the power settings increased and the time to reach baseline temperature $\left(37^{\circ} \mathrm{C}\right)$ showed no significant differences between all groups as shown in Figures $(4,5)$.

Table (3): Mean ranks and p-value of Kruskal -Wallis test for temperature $37^{\circ} \mathrm{C}$ rise at different powers with mean time in second to reach $37 \mathrm{c}$.

\begin{tabular}{cccc}
\hline Power in Watt & Meantime in second to reach $47^{\circ} \mathrm{C} \mathrm{c}$ & Std. Deviation & Mean rank \\
\hline 2 & 59 & 0.9 & 742.92 \\
3 & 59.1 & 0.91 & 769.89 \\
4 & 59.1 & 0.9 & 774.35 \\
5 & 59.1 & 0.93 & 731.60 \\
6 & 58.9 & 0.9 & 733.73 \\
p-value & & & 0.565 \\
\hline
\end{tabular}


Table (4): Mann-Whitney test for temperature $37^{\circ} \mathrm{C}$ at different power

\begin{tabular}{cc}
\hline Relation between Different power in watts & p-value \\
\hline $2-3$ & 0.414 \\
$2-4$ & 0.340 \\
$2-5$ & 0.734 \\
$2-6$ & 0.772 \\
$3-4$ & 0.133 \\
$3-5$ & 0.248 \\
$3-6$ & 0.383 \\
$4-5$ & 0.197 \\
$4-6$ & 0.228 \\
$5-6$ & 0.960 \\
\hline
\end{tabular}

Statically significant at $p \leq 0.005$

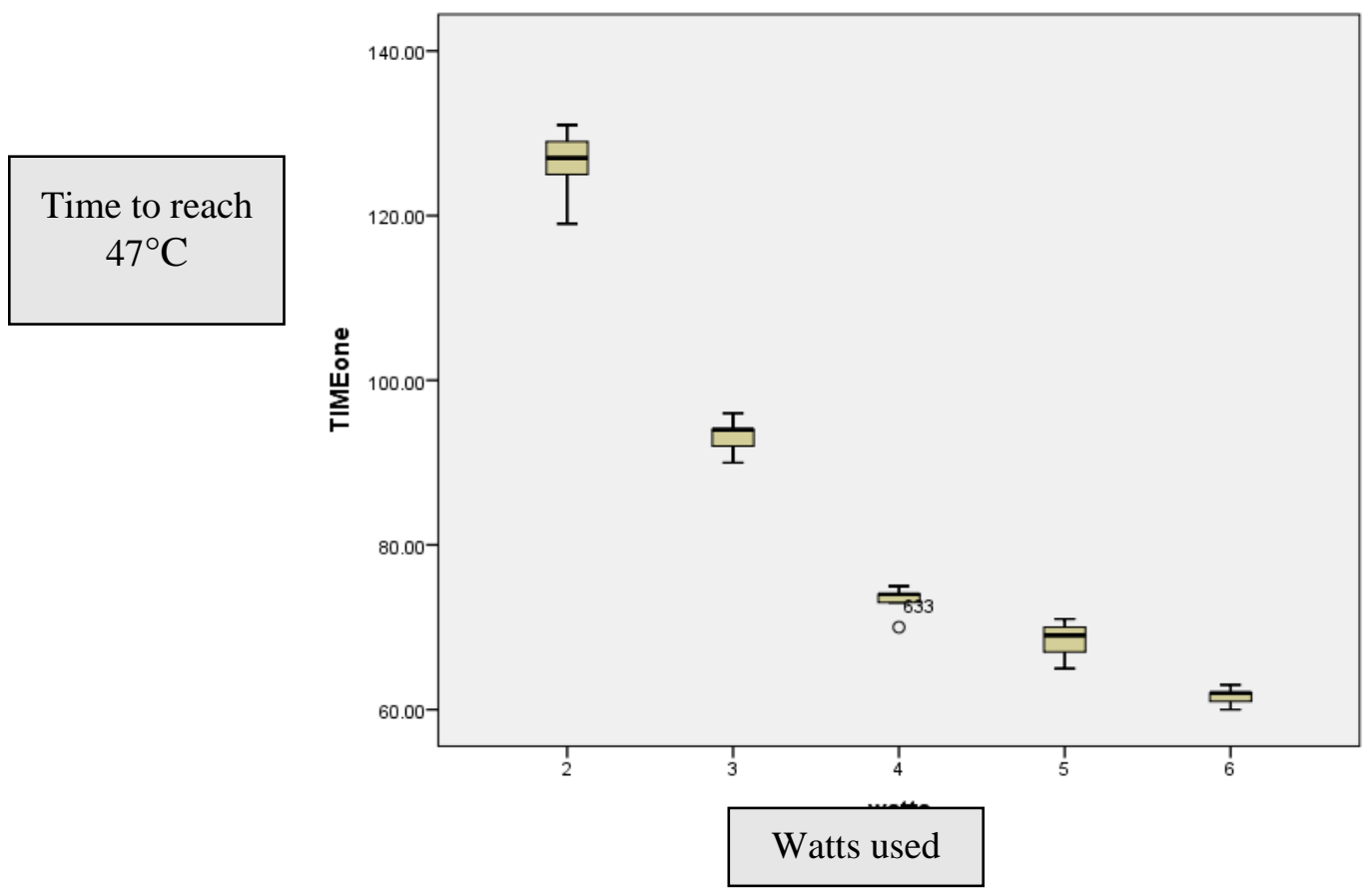

Figure (4): Relation ship between watts used and time to reach $47^{\circ} \mathrm{C}$ 


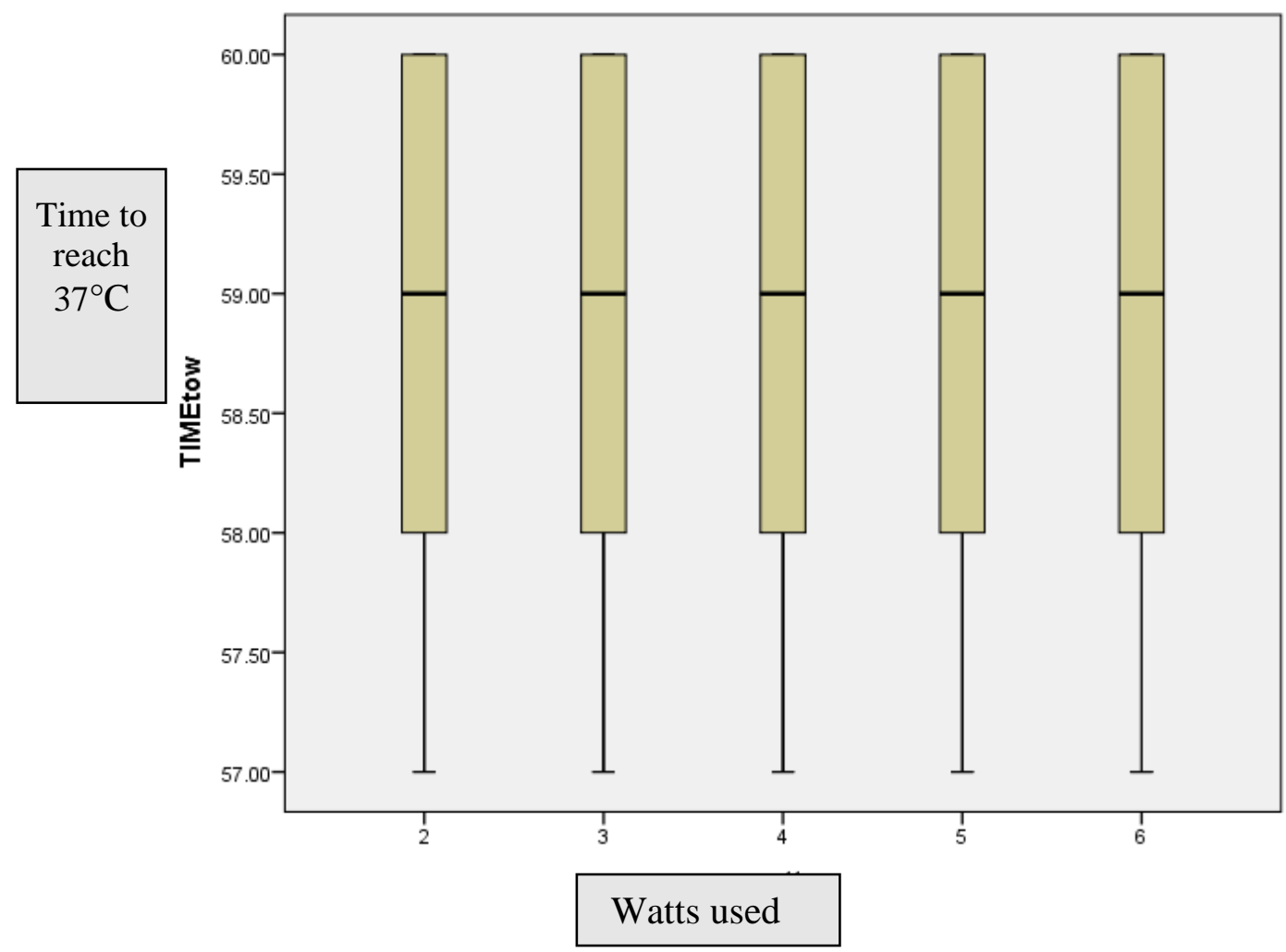

Figure (5): Relationship between watts used and time needed to drop to $37^{\circ} \mathrm{C}$

\section{DISCUSSION}

The eradication of microorganisms by diode laser though established by numerous studies has some aspects when used for the treatment of peri-implant disease in that the laser beam may disturb the implants titanium surface ${ }^{(29-31)}$. Such a type of laser and with its power parameters should always be adjusted to avoid the negative changes that may affect the process of osseointegration. The present study inspected the heat generated after exposer to a pulsed diode laser in wave lengths 1064 in an in-vitro model. The results revealed that the exposure power of the laser should be adjusted carefully to avoid any changing effects on the biological and mechanical levels of the implant. Such results may fluctuate if different bone models are used and if different types of implant systems are used due to differences in the reaction of the laser by the surface form ${ }^{(32)}$. In some studies, bone injury by heat induction was carried out in rabbits causing adverse effects on living bone when the temperature rised above $47^{\circ} \mathrm{C}$ for $60 \mathrm{~s}$ affecting the ability of bone to regenerate $(27,33,34)$. The overheating at the bone-implant interface may cause bone death and compromise the bone's ability to stay alive as a differentiated tissue ${ }^{(35)}$. Temperatures be- 
yond $50 \mathrm{C}$ are widely believed to promote thermonecrosis ${ }^{(36-38)}$. It has been established that bone is more sensitive to temperature than formerly supposed, and it will withstand a threshold temperature ranging from $44^{\circ} \mathrm{C}$ to $47^{\circ} \mathrm{C}$ for only 1 minute without impaired bony regeneration. However, increasing the temperatures but lower than $47^{\circ} \mathrm{C}$ did not appear to affect the bone tissue at the microscopic level, but vascular harm did occur as evidenced by increased capillary leakage at even lower temperatures ${ }^{(27)}$. The result of this study came parallel with the results of Matys, J., et al whom showed that the temperature on the implant interface increases as the laser power increased (32). Leja, C., et al showed that lower laser power settings and pulsed rather than continuous mode took longer to reach critical temperature ${ }^{(39)}$. The main limitation of the current study was the lack of evidence of this type of laser on the surface topography of implant. However, there are studies in this field that can give us some clue on its effects. Particular care should be taken when using lasers in its different types for treatment of peri-implantitis such as Er: YAG, $\mathrm{CO}_{2}$, Diode, Er,Cr:YSGG(Erbium, Chromium doped Yttrium Scandium Gallium Garnet) and Nd:YAG (Neodymium-Doped Yttrium Aluminium Garnet ${ }^{(40,41)}$.

\section{REFERENCES}

1. Bedrossian, E., Do Dental Implant Width and Length Matter? Compend Contin Educ Dent, 2020. 41(7): p. e1-e5.
2. Gupta, R., N. Gupta, and K.K. Weber, Dental Implants, in StatPearls. 2021, StatPearls Publishing Copyright (C) 2021, StatPearls Publishing LLC.: Treasure Island (FL).

3. Romanos, G.E., R. Delgado-Ruiz, and A. Sculean, Concepts for prevention of complications in implant therapy. Periodontol 2000, 2019. 81(1): p. 7-17.

4. Ettl, T., et al., Implant survival or implant success? Evaluation of implant-based prosthetic rehabilitation in head and neck cancer patients-a prospective observational study. Clin Oral Investig, 2020. 24(9): p. 30393047.

5. Misch, C.E., et al., Implant success, survival, and failure: The International Congress of Oral Implantologists (ICOI) Pisa Consensus Conference. Implant Dent, 2008. 17(1): p. 5-15.

6. Karlsson, K., et al., Occurrence and clustering of complications in implant dentistry. Clin Oral Implants Res, 2020. 31(10): p. 1002-1009.

7. Khoury, F., et al., Surgical treatment of periimplantitis - Consensus report of working group 4. Int Dent J, 2019. 69 Suppl 2: p. 1822.

8. Renvert, S., A.M. Roos-Jansåker, and G.R. Persson, Surgical treatment of periimplantitis lesions with or without the use of a bone substitute-a randomized clinical trial. J Clin Periodontol, 2018. 45(10): p. 12661274. 
9. Koldsland, O.C., A.A. Scheie, and A.M. Aass, Prevalence of peri-implantitis related to severity of the disease with different degrees of bone loss. J Periodontol, 2010. 81(2): p. 231-8.

10.Rühling, A., et al., Treatment of subgingival implant surfaces with Teflon-coated sonic and ultrasonic scaler tips and various implant curettes. An in vitro study. Clin Oral Implants Res, 1994. 5(1): p. 19-29.

11.Mombelli, A., et al., Treatment of periimplantitis by local delivery of tetracycline. Clinical, microbiological and radiological results. Clin Oral Implants Res, 2001. 12(4): p. 287-94.

12.Heitz-Mayfield, L.J. and N.P. Lang, Antimicrobial treatment of peri-implant diseases. Int $\mathbf{J}$ Oral Maxillofac Implants, 2004. 19 Suppl: p. 128-39.

13.Zablotsky, M.H., D.L. Diedrich, and R.M. Meffert, Detoxification of endotoxincontaminated titanium and hydroxyapatitecoated surfaces utilizing various chemotherapeutic and mechanical modalities. Implant Dent, 1992. 1(2): p. 154-8.

14.Renvert, S., A.M. Roos-Jansåker, and N. Claffey, Non-surgical treatment of peri-implant mucositis and peri-implantitis: a literature review. J Clin Periodontol, 2008. 35(8 Suppl): p. 305-15.

15.Albaker, A.M., et al., Effect of photodynamic and laser therapy in the treatment of periimplant mucositis: A systematic review. Photodiagnosis Photodyn Ther, 2018. 21: p. 147-152.
16. Ulu, M., et al., Antibiofilm efficacies of cold plasma and er: YAG laser on Staphylococcus aureus biofilm on titanium for nonsurgical treatment of peri-implantitis. Niger J Clin Pract, 2018. 21(6): p. 758765.

17. Pirnat, S., Versatility of an $810 \mathrm{~nm}$ Diode Laser in Dentistry: An Overview. J Las and Health Academy, 2007. (4): p. 1 -8.

18. Mathur, E., et al., Diode Laser Excision of Oral Benign Lesions. J Lasers Med Sci, 2015. 6(3): p. 129-32.

19. Stubinger, S., et al., [Soft tissue surgery with the diode laser--theoretical and clinical aspects]. Schweiz Monatsschr Zahnmed, 2006. 116(8): p. 812-20.

20. Fornaini, C., et al., Different laser wavelengths comparison in the second-stage implant surgery: an ex vivo study. Lasers Med Sci, 2015. 30(6): p. 1631-9.

21. El-Kholey, K.E., Efficacy and safety of a diode laser in second-stage implant surgery: a comparative study. Int J Oral Maxillofac Surg, 2014. 43(5): p. 633-8.

22. Lerario, F., et al., Non-surgical periodontal treatment of peri-implant diseases with the adjunctive use of diode laser: preliminary clinical study. Lasers Med Sci, 2016. 31(1): p. 1-6.

23. Zingale, J., et al., Effectiveness of root planing with diode laser curettage for the treatment of periodontitis. J Calif Dent Assoc, 2012. 40(10): p. 786-93. 
24. Iyer, S., C. Weiss, and A. Mehta, Effects of drill speed on heat production and the rate and quality of bone formation in dental implant osteotomies. Part II: Relationship between drill speed and healing. Int J Prosthodont, 1997. 10(6): p. 536-40.

25. Berman, A.T., et al., Thermally induced bone necrosis in rabbits. Relation to implant failure in humans. Clin Orthop Relat Res, 1984. 186: p. 284-92.

26. Möhlhenrich, S.C., et al., Heat generation and drill wear during dental implant site preparation: systematic review. $\mathrm{Br} \mathrm{J}$ Oral Maxillofac Surg, 2015. 53(8): p. 679-89.

27. Eriksson, A.R., T. Albrektsson, and B. Albrektsson, Heat caused by drilling cortical bone. Temperature measured in vivo in patients and animals. Acta Orthop Scand, 1984. 55(6): p. 629-31.

28.Malmqvist, S., et al., Using $445 \mathrm{~nm}$ and 970 nm Lasers on Dental Implants-An In Vitro Study on Change in Temperature and Surface Alterations. Materials (Basel, Switzerland), 2019. 12(23): p. 3934.

29.Black, J., Biological Performance of Materials. 2 ed. 1992, New York: Marcel Dekker. 400.

30.Park, et al., Effects of laser irradiation on machined and anodized titanium disks. Int $\mathbf{J}$ Oral Maxillofac Implants, 2012. 27(2): p. 265-72.

31. Hindy, A., F. Farahmand, and F.S. Tabatabaei, In vitro biological outcome of laser application for modification or processing of titanium dental implants. Lasers Med Sci, 2017. 32(5): p. 1197-1206.

32. Matys, J., et al., Thermodynamic effects after Diode and Er:YAG laser irradiation of grade IV and V titanium implants placed in bone - an ex vivo study. Preliminary report. Biomed Tech, 2016. 17(10): p. 2015-0135.

33. Kniha, K., et al., Temperature Threshold Values of Bone Necrosis for ThermoExplantation of Dental Implants-A Systematic Review on Preclinical In Vivo Research. Materials (Basel), 2020. 13(16).

34. Semez, G., et al., Effect of the laser beam on implant site preparation: a preliminary pilot study. Rom J Morphol Embryol, 2018. 59(3): p. 861-867.

35. Gross, M., B.Z. Laufer, and Z. Ormianar, An investigation on heat transfer to the implant-bone interface due to abutment preparation with high-speed cutting instruments. Int J Oral Maxillofac Implants, 1995. 10(2): p. 207-12.

36. Bachus, K.N., M.T. Rondina, and D.T. Hutchinson, The effects of drilling force on cortical temperatures and their duration: an in vitro study. Med Eng Phys, 2000. 22(10): p. 685-91.

37. Salimov, F., et al., The effects of repeated usage of implant drills on cortical bone temperature, primary/secondary stability and bone healing: A preclinical in vivo micro-CT study. Clin Oral Implants Res, 2020. 31(8): p. 687-693. 
38. Shakouri, E., et al., Experimental and analytical investigation of the thermal necrosis in high-speed drilling of bone. Proc Inst Mech Eng H, 2014. 228(4): p. 330-41.

39. Leja, C., et al., Thermodynamic effects of laser irradiation of implants placed in bone: an in vitro study. Lasers Med Sci, 2013. 28(6): p. 1435-40.
40. Guarnieri, R., et al., Effect of a laser-ablated micron-scale modification of dental implant collar surface on changes in the vertical and fractal dimensions of peri-implant trabecular bone. Clin Ter, 2020. 171(5): p. e385-e392.

41. Chegeni, E., et al., Effect of an Er,Cr:YSGG Laser on the Surface of Implants: A Descriptive Comparative Study of 3 Different Tips and Pulse Energies. Dent J (Basel), 2020. 8(4). 